\title{
Cultural Foundations for Ecological Restoration on the White Mountain Apache Reservation
}

\author{
$\underline{\text { Jonathan Long, Aregai Tecle }}{ }^{1}$, and Benrita Burnette
}

\begin{abstract}
Myths, metaphors, and social norms that facilitate collective action and understanding of restoration dynamics serve as foundations for ecological restoration. The experience of the White Mountain Apache Tribe demonstrates how such cultural foundations can permeate and motivate ecological restoration efforts. Through interviews with tribal cultural advisors and restoration practitioners, we examined how various traditions inform their understanding of restoration processes. Creation stories reveal the time-honored importance and functions of water bodies within the landscape, while place names yield insights into their historical and present conditions. Traditional healing principles and agricultural traditions help guide modern restoration techniques. A metaphor of stability illustrates how restoration practitioners see links among ecological, social, and personal dimensions of health. These views inspire reciprocal relationships focused on caretaking of sites, learning from elders, and passing knowledge on to youths. Woven together, these cultural traditions uphold a system of adaptive management that has withstood the imposition of non-indigenous management schemes in the $20^{\text {th }}$ century, and now provides hope for restoring health and productivity of ecosystems through individual and collective efforts. Although these traditions are adapted to the particular ecosystems of the Tribe, they demonstrate the value of understanding and promoting the diverse cultural foundations of restoration.
\end{abstract}

\section{INTRODUCTION}

Although ecologists have increasingly recognized the importance of cultural knowledge in guiding ecological restoration, they often dwell on its applicability to intensively managed or altered landscapes. The term "cultural landscape" was crafted to demonstrate that culture and nature co-evolve (Naveh 1998). Unfortunately, common usage of the term implies that some landscapes are not "cultural," and that the cultural dimensions of restoration may be more significant in places, "like Europe, where cultural landscapes are the norm" than in much of North America (Society for Ecological Restoration Science and Policy Working Group 2002). However, "as every ethnographer eventually comes to appreciate, geographical landscapes are never culturally vacant," as culture mediates how landscapes are observed, how they are used, and how they are represented (Basso 1996: 75). Consequently, cultural traditions should not be viewed merely as possible constraints on restoration efforts, but rather as potential guiding forces behind such endeavors.

Advocates of adaptive management in particular have emphasized the importance of cultural elements such as metaphors, myths, and group dynamics (Michael 1995). After considering the underpinnings of contemporary ecological management, they have concluded: "We need new myths, new words, and meaning in our language and quickly" (Gunderson et al. 1995). Rather than abandoning the artistry of restoration, they contend we need to restyle it. Some philosophers have considered this call by turning to the works of Aldo Leopold as inspiration for a "land ethic" (Callicott 1989, Des Jardins 1997). Leopold (1939) himself spoke of replacing the "violent" pioneer mentality by cultivating an ecological mind enlightened through scientific inquiry. Other writers have advised that traditional ecological knowledge, having co-evolved with ecosystems, may provide a strong foundation for ecological restoration (LaDuke 1994, Kimmerer 2000, Turner et al. 2000). Consequently, integrating the practices, institutions, and worldviews of traditional ecological knowledge with scientific learning can stimulate the process of adaptive management (Berkes et al. 2000). Thoughtful, collaborative efforts to blend traditional ecological knowledge with Western ecological science may ultimately help supplant the often artificial

\footnotetext{
${ }^{1}$ Northern Arizona University
} 
distinctions between "natural" and "cultural" with a unified concept of "eco-cultural restoration" (Martinez 1995).

Fig. 1. Location of the White Mountain Apache Reservation in Arizona.

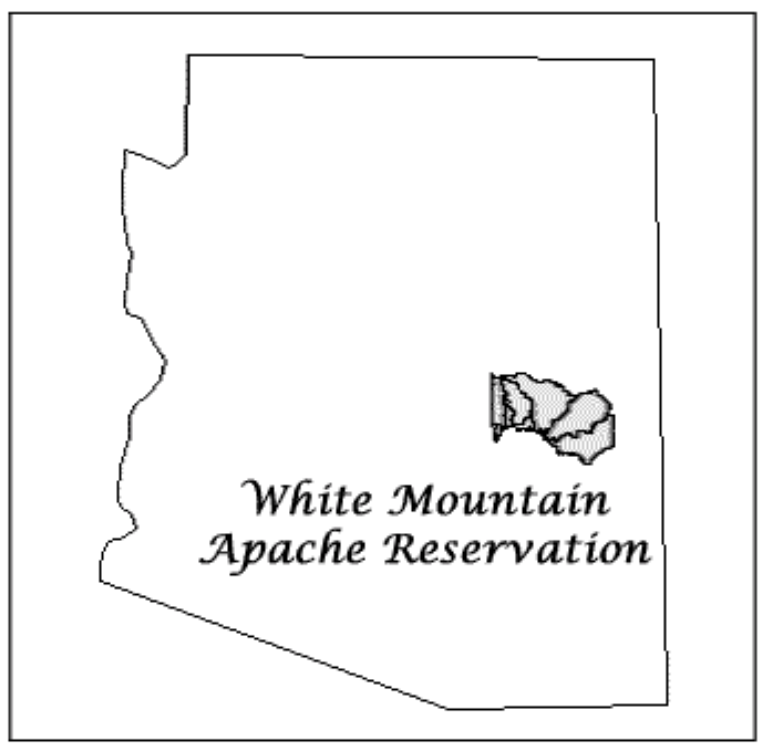

For the White Mountain Apache Tribe of east-central Arizona (Fig. 1), contemporary ecological restoration signifies the harmonization of modern resource management with traditional values. At the policy level, the Tribe set aside payment for the U.S. Government's past mismanagement of tribal forests and rangelands to create a permanent Land Restoration Fund (Long 1998). The code establishing the fund states the goal of restoring the Tribe's lands and waters to the levels of health and productivity that existed before mismanagement. At the organizational level, the Tribal Council has instituted several governing bodies that help coordinate these efforts. A Land Restoration Board of tribal members allocates funds among projects. The Tribal Cultural Advisory Board, composed of esteemed tribal elders, provides direction for restoration activities, and a representative of that group sits on a Plan and Project Review Panel that reviews all projects undertaken on the Reservation (Welch 1998). At the individual level, tribal members working for the Tribe's Watershed Program and other departments conduct restoration efforts with guidance from these governing bodies. Outside researchers have assisted these efforts through a framework of participatory action research, which helps develop science, policy, and organization that fit the needs of the local community (Lal et al. 2001). Numerous policies ensure that any research meets Tribal priorities, enhances the local knowledge base, and remains under Tribal control.

To better understand how cultural traditions have shaped the Tribe's program of ecological restoration, we interviewed cultural advisors (tribal members recognized in the community as knowledgeable of cultural traditions) at ongoing restoration sites to explore their views on restoring riparian wetlands. Although cultural advisors are wary of revealing sensitive cultural information, they recognize the importance of sharing the Tribe's ecological restoration efforts with outsiders. By relating their impressions to methods employed by the Tribal Watershed Program in assessing and treating riparian wetlands, we demonstrate how contemporary restoration efforts build upon long-standing traditions. Although we cannot adequately convey the breadth, complexity, or subtlety of Apache ecological knowledge, we present these findings to demonstrate the potential importance of cultural traditions in shaping all aspects of ecological restoration. This pervasiveness helps us understand why tribal members view management strategies that ignore or undermine cultural traditions as doomed to failure.

\section{CONCEIVING THE NEED FOR ECOLOGICAL RESTORATION}

\section{Vision for the land}

White Mountain Apache culture emphasizes the infusion of the physical world with mental and spiritual dimensions. Apache language demonstrates the inseparability of the two: the root word $n i$ ' can refer to either "mind" or "land" (Bray 1999). A complex interaction occurs between these interior and exterior landscapes, as places remind people how to live right (Basso 1996), and people's behaviors affect the conditions of places. Of these places, water bodies hold exceptional significance, as nearly half of the place names in many regions of aboriginal Apache lands are associated with water bodies or wetland organisms (Grenville Goodwin Placenames Project 1997).

The first tale in the cycle of White Mountain Apache creation stories establishes the mythological importance of water: "'How will it breathe, this earth?' Then came Black Thunder to that place, and he gave 
the earth veins. He whipped the earth with lightning and made water start to come out" (excerpt from The Earth is Set Up, as told by Palmer Valor in Goodwin 1994: 2). The metaphor of water as the breath of the earth is central to the Tribe's vision of restoration. Practitioners see restoration as the process of "bringing life back to the streams," through methods that help the springs to "breathe again" (Long and Burnette 2000).

In suggesting how to promote learning in ecological management, Michael (1995) notes that metaphors "can change the atmosphere in which issues are debated and actions selected and implemented." In this light, we contrast the Tribe's metaphor of restoration with a common description offered by some ecologists: "Restoration can then be viewed as an attempt to force transitions towards a desired state, and as requiring knowledge of the variables that need to be manipulated to achieve these transitions" (Hobbs and Norton 1996, emphasis added). This description implies that humans dominate a mechanistic process, while the tribal metaphor portrays nature as active in an organic process, with humans in a subsidiary role. Indeed, this mechanistic description of restoration seems to have scarcely evolved from the pioneer mentality that Leopold disdained. Although he claimed that ecology offered the only language adequate to guide land use (Leopold 1999), recent skeptics have contended the taint of industrial economics renders the discipline unsuitable as a paradigm for redeeming human relationships with the earth (Jackson 1997).

In contrast, the conviction that water bodies are living beings elevates discussions about their restoration. Nearly a century ago, Western Apaches had explained to an anthropologist, "water itself has life; witness the way it ripples and flows in a river, the noise it makes in flood" (Goodwin 1938: 25). Cultural advisors describe wetlands in favorable condition using indicators that reveal the vitality that water brings to a semi-arid landscape. For them, healthy streams are visibly alive, marked by the vigor and greenness of wetland plants, the bustle of diverse forms of wildlife, an abundance of water, and vibrant memories of living off the land. A wetland plant, common reed (Phragmites australis) figures prominently in creation stories, and pollen from cattails (Typha spp.) is a sacrament in tribal ceremonies. Conversely, one advisor described a wetland in deteriorated condition as "lifeless" and "dreary." When restoration is viewed as influencing life-sustaining processes, it assumes more significance than as a vehicle for testing ecological theory.

Creation stories provide insights into the tribal understanding of the processes of ecological deterioration and recovery. For example, one story describes how a catastrophic flood left the earth without soil, plants, or physical structure, so that it was unsuitable for people to live. However, through a primeval restoration, the world filled with living things, starting with animals, plants, and mountains:

After the water had gone, it left the
earth so bare that it did not look good,
there was nothing growing. But now
they planted the seeds of all those
plants Bear had given them, and other
trees and grasses; all the plants that
are growing now like cottonwood,
willow, tc'ilxe (a bush), jojoba, pines,
cedars, manzanitas, oaks, all kinds. .
. Level, without mountains, it did not
look well. So they set up mountains,
and on them aspen and spruce and
pine started to grow. Bear gave them
dasinexuc (a cactus), nadatbai (a
mescal) and all the mescals and foods
that we still eat today. (Excerpt from
The Flood as told by Anna Price in
Goodwin $1994: 51$.

The story lays a foundation for understanding riparian ecology, because floods are the most prominent form of disturbance in riparian ecosystems. This passage identifies two key riparian plants, cottonwood and willow, that are quick to colonize riparian areas after disturbance. It also establishes a precedent for both revegetation and structural treatments to restore the land. This archetypal vision of restoration is distinctly suited to the diverse vegetation and rugged topography of the Tribe's mountain homeland.

\section{Process of deterioration}

Deterioration of water bodies is a great concern among advisors, both because they represent the loss of a critical resource, and because they point to violations of cultural norms. The drying of sites that were named for the abundance of water has been interpreted as the result of social transgressions, such as greediness and neglect (Basso 1996). Tribal language specialist Beverly Malone, who translates recordings of elders, notes that many old stories depict the loss of springs as one of the signs of social collapse. 
For advisors, the legacy of watershed manipulations led by the U.S. Government demonstrates how greediness has led to deterioration. Symbolizing these transgressions are the poisoning and girdling of stately cottonwood trees along the streams in Tribal communities in a failed attempt to increase water yield to non-Indian cities and farms downstream (Long 2000). Advisors discussing stream restoration frequently recall this event, now 40 years in the past, and point to it as a primary cause of present-day ecological deterioration. Moreover, the event has a strong moral dimension. Because it involved "wanton destruction of a valued natural resource," some community members associated this program with witchcraft (Basso 1970). Present-day ecological restoration activities that involve altering streamside vegetation or applying herbicides continue to confront the legacy of deep skepticism induced by the cottonwood-poisoning incident.

Another belief that permeates restoration efforts is that neglect by humans may cause some elements of the ecosystem to decline (Kimmerer 2000). Advisors thought it likely that the decline of traditionally harvested riparian associates, such as mulberry (Morus microphylla), reed, and tobacco (Nicotiana spp.) might be a consequence, as well as a cause, of reduced use. Research has shown that the reworking of the soil associated with traditional harvesting activities may help stimulate growth of the desired plants (Turner et al. 2000). Creation stories suggest that such harvesting may even be an obligation for Apaches: "This is the way they made the earth for us. This is the way all these wild fruits and foods were raised for us, and this is why we have to use them because they grow here" (excerpt from The Earth is Set Up, as told by Palmer Valor in Goodwin 1994: 2). Such a perspective reinforces the belief that cures for deterioration may lie not always in curtailing human influence, but rather in upholding indigenous land management practices (Nabhan 1997).

\section{Process of recovery}

Tribal efforts to restore ecological health share a language used to describe restoration of physical and mental health. For example, advisors may use the term gozhoo to describe a healthy wetland condition. The term also describes the recuperation of individual health:

When ancestral knowledge works to give beneficial perspective and fresh recognition that trying times can be dealt with successfully and eventually overcome-persons thus heartened may announce that relationships characterized by 'pleasantness and goodness' (gozhoo) have been restored between themselves and their surroundings. (Basso 1996: 91-92.)

Some ecologists have protested extending the lexicon of health to ecosystems, based on the contention that ecosystem health is far more complex and difficult to measure than human health (Kelly and Harwell 1990). Although Western Apaches are particularly mindful of the need to choose words wisely (Basso 1996), advisors seem to find the metaphor appropriate, at least in part because the term helps to capture the complexity of natural processes. Demonstrating the power of the metaphor are the striking parallels between ecological stability and the Western Apache concept of mental stability. Stability of mind enables the bearer to cope with the stresses and hazards of life (Basso 1996), as the stability of an ecosystem allows it to cope with the stresses and disturbances of its environment. Stability of mind has three components: resistance, resilience, and smoothness (Basso 1996). The first two terms have clear equivalents in ecological contexts (Grimm and Wissel 1997), but ecological vocabularies do not typically include the third. "Smoothness," describing an area free of obstructions (Basso 1996), refers to the capacity of a system to avoid perturbations, rather than resisting them or recovering quickly from them. Applied to a riparian setting, a "smooth" ecosystem may be one that avoids disruption by floods, such as a well-developed ciénega. For this kind of wetland, a thick cover of sedges may be "smoother" than one dominated by woody shrubs such as willows. The sedges lie down like a carpet (Fig. 2), whereas willows may introduce turbulence, catch debris, and cause local erosion (Hendrickson and Minckley 1984, Lyons et al. 2000).

\section{GUIDELINES FOR ECOLOGICAL RESTORATION}

As the languages of ecological and individual health are related, so are the strategies for restoring the health of ecosystems and individuals. The traditional model of healing maintains that patients are not passive and inanimate, but rather must be active agents in their own recovery. Advisors noted that treatment decisions must take into account the patient's state of mind and willingness to be healed, as well as environmental 
factors that could influence the outcome. An Elder Bernice Endfield advised her grandson, Delbin, who coordinates restoration projects, "Go slowly; listen to the land and it will tell you what to do." This statement explains two essential ingredients for successful restoration. First, the land must have demonstrated its willingness to be healed to the practitioner; advisors have described this awareness as "having a vision for the land." Second, the practitioner must have patience in helping this vision become reality.

Fig. 2. A luxuriant carpet of herbaceous wetland plants render this reach of Carrizo Creek relatively "smooth,"-able to withstand large floods without experiencing erosion. A large wildfire had struck the watershed above this site a year before this photo was taken, yet the channel did not degrade and the wetland plants were able to quickly stitch the fresh sediments into streambanks.

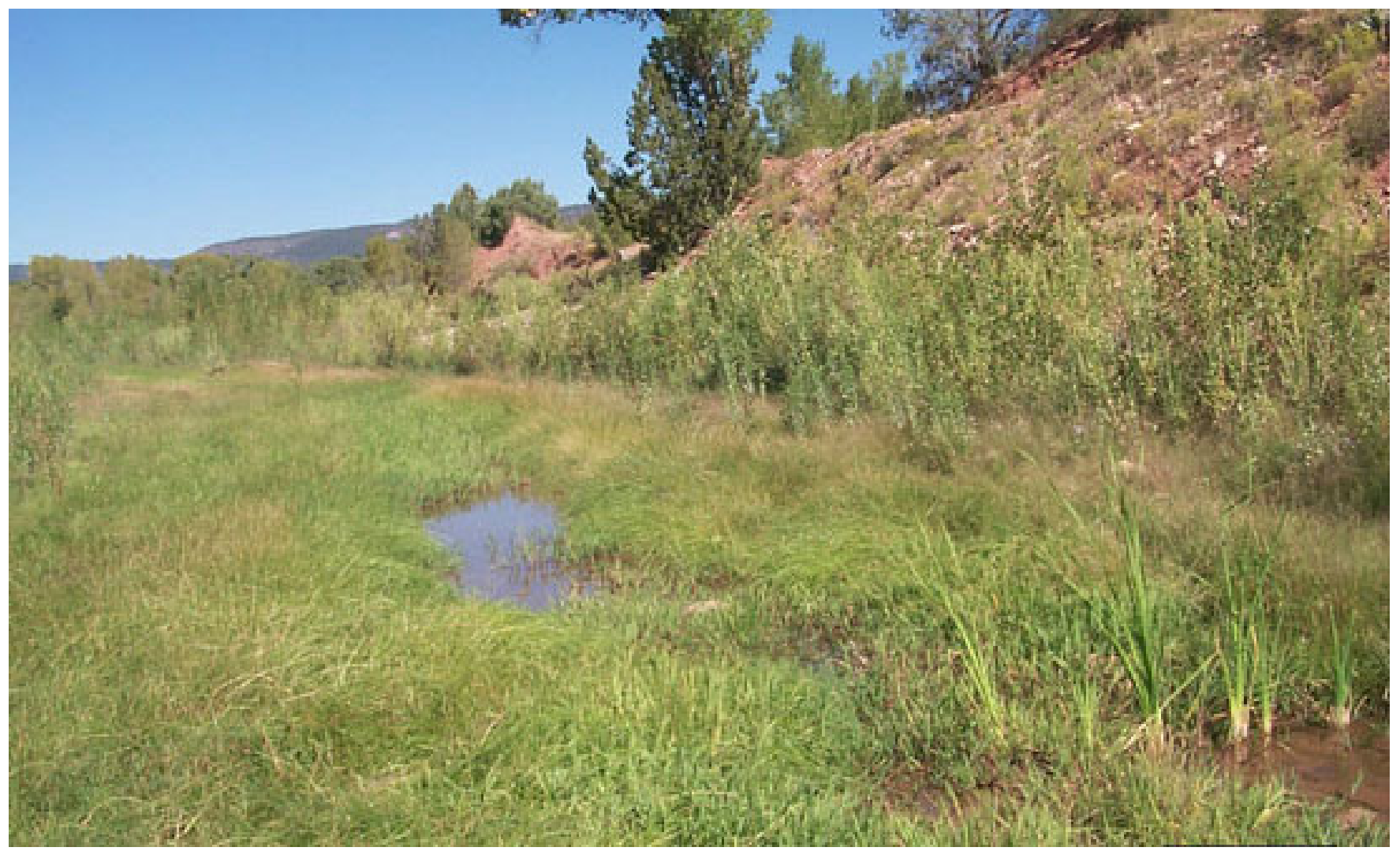

When advisors have not supported a proposed intervention, they have recommended instead, "Let Mother Nature take care of herself." This response reflects a conviction that the cause of deterioration was non-physical, that the proposed treatment would be inopportune, or that the perceived deterioration was beyond the proponent's competency to treat. This attitude has been called "environmental therapeutic nihilism," a term derived from skepticism toward medical interventions (Hargrove 1992). That such skepticism would occur in White Mountain Apache attitudes toward environmental matters is not surprising, as it also surfaces in attitudes toward health care. Decisions to seek medical care by hospital physicians reflect similar considerations of the nature of the illness and the relative competence of the practitioner (Everett 1971).

These views underscore the value of projects that demonstrate a proponent's capacity to treat a particular problem. When facing unmistakably physical problems such as erosion, advisors supported active interventions including fencing, placement of gravels and rocks, streambank recontouring, selective removal of shrubs, and transplanting. Although methods that involve heavy equipment might evoke past misdeeds by the U.S. Government, many advisors expressed confidence in such treatments based on their past 
experiences as farmers and as workers on conservation projects. Cultural advisors can embrace such nontraditional tools such as bulldozers in restoration activities because they regard the choice of tools as far less important than the mindset of the person employing them. The overriding importance of proper mindset (often described as "having wisdom" and "showing respect") is a distinctive feature of traditional ecological knowledge (Ford and Martinez 2000, Turner et al. 2000).

Because advisors perceive deterioration as a long-term process, they view quick fixes with skepticism and believe that practitioners must demonstrate commitment, patience, and adaptability. A heavy equipment operator on one project explained his view of restoration: "You go to a place and do some work for it. You let it rest, and then you come back to it to see what it has done. Then it thanks you." Because nature directs the recovery, practitioners may not plan a full course of treatment until observing how a site responds. Although uncertainty is a bane of scientific management, accepting it is a sign of a healthy environment for social learning (Michael 1995). Recognizing that science does not offer all the answers to restoration challenges may give practitioners more faith in their abilities, rather than less.

\section{Treatment methods}

Because indigenous land management activities center on gathering and farming, ecological restoration draws from agricultural practices. Although the characterization of restoration as "gardening with wild species in natural mosaics" (Allen and Hoekstra 1992) seems disparaging to some commentators (Hobbs and Norton 1996, van Diggelen et al. 2001), it could be an epitome of Western Apache agriculture. Tribal legends often do not stress the difference between domesticated crops and wild plants; for example, the phrase "where crops and ripe fruits are continual" is often used in ritual to describe a beautiful land (Goodwin 1994). Emphasizing distinctions between plant gathering and agriculture reinforces the artificial dichotomy of "natural" and "cultural," as foragers frequently employ a range of habitat management techniques (Turner et al. 2000). Consequently, a striking similarity to agriculture does not belittle the scope of restoration, but rather demonstrates its ancient roots. In trying to unify theoretical and applied ecology, Allen and Hoekstra (1992) point out that a scientifically sound restoration strategy often applies "ordinary" techniques.
Describing her mother's caretaking practices, advisor Eva Watt explained the richness of Western Apache agricultural knowledge and its applicability to contemporary restoration. As her mother was born in 1864, 7 years before the establishment of the Reservation, these practices are long-lived. She provided several examples of these caretaking activities:

- Reseeding, typically of crop plants;

- Transplanting desired plants, while noting the importance of soil properties and elevation to determine areas to which the plant could be relocated;

- Thinning and removal of vegetation, particularly woody plants;

- Removing debris from spring sources to maintain water quality;

- Protecting sensitive areas from animals with rocks, fences, and living hedges (composed of reeds in one example);

- Letting fields lie fallow to restore their productivity;

- Burning plants, particularly riparian species such as mulberry and willows (Salix spp.), to stimulate shoot growth; and

- Applying layers of different-sized rocks and plant materials along streambanks to stem erosion, with the objectives of preventing damage to agricultural works and protecting water quality by steering flows away from erodible formations.

All these techniques have contemporary equivalents employed by the Tribal Watershed Program. In particular, her description of traditional streambank erosion control is remarkably similar to how restoration practitioners have treated downcutting in wet meadows by augmenting riffle formations with layers of gravels and sedge transplants (Fig. 3). This particular practice also incorporates the cultural tradition of using various senses to assess a site's condition. The quieting of the flowing water indicates when the riffle has reached a stable form.

Fire has historically been used to manage uplands, and advisors did remark on the effectiveness of burning to maintain grasslands suitable for hunting and grazing. In the latter part of the $20^{\text {th }}$ century, the Reservation has been renowned for the early and widespread use of prescribed fire to reduce the risk of wildfires (Pyne 1997). However, the interactions among fire, upland conditions, and riparian conditions are extremely 
complex and variable across different landscape types (Neary et al. 2003). Cultural attitudes toward fire are similarly complex, reflecting the nature of this element as a force of both destruction and rejuvenation. Government resource managers appointed to administer aboriginal lands have often dismissed aboriginal burning as reckless, while failing to recognize that traditional burning practitioners possessed sophisticated understanding of ecological dynamics (Lewis 1989). For example, a Superintendent of the Fort Apache Agency once derisively asserted, "Sometimes these fires are started by some old superstitious Indian who believes that fires bring rain" (Crouse 1902). However, a scientific basis for this "superstition" may lie in the "building evidence that severely burned areas function as heat islands that accelerate thunderstorm development in mountainous regions" (Neary and Gottfried 2002). Although Apaches clearly have long recognized the potential benefits of fire, advisors caution that fire is a dangerous element that must be shown great respect.

Fig. 3. Trampling by horses and elk had induced bank erosion and channel incision along Soldier Creek by 1993 (upper left). Three years of treatments, starting in 1998, including electric fencing, sedge transplants, and placement of rock-gravel riffle formations (lower left), stimulated dramatic recovery of channel stability and aquatic vegetation (right). Young tribal members have conducted restoration work at the site each year as part of the Watershed Program's summer ecology camps.

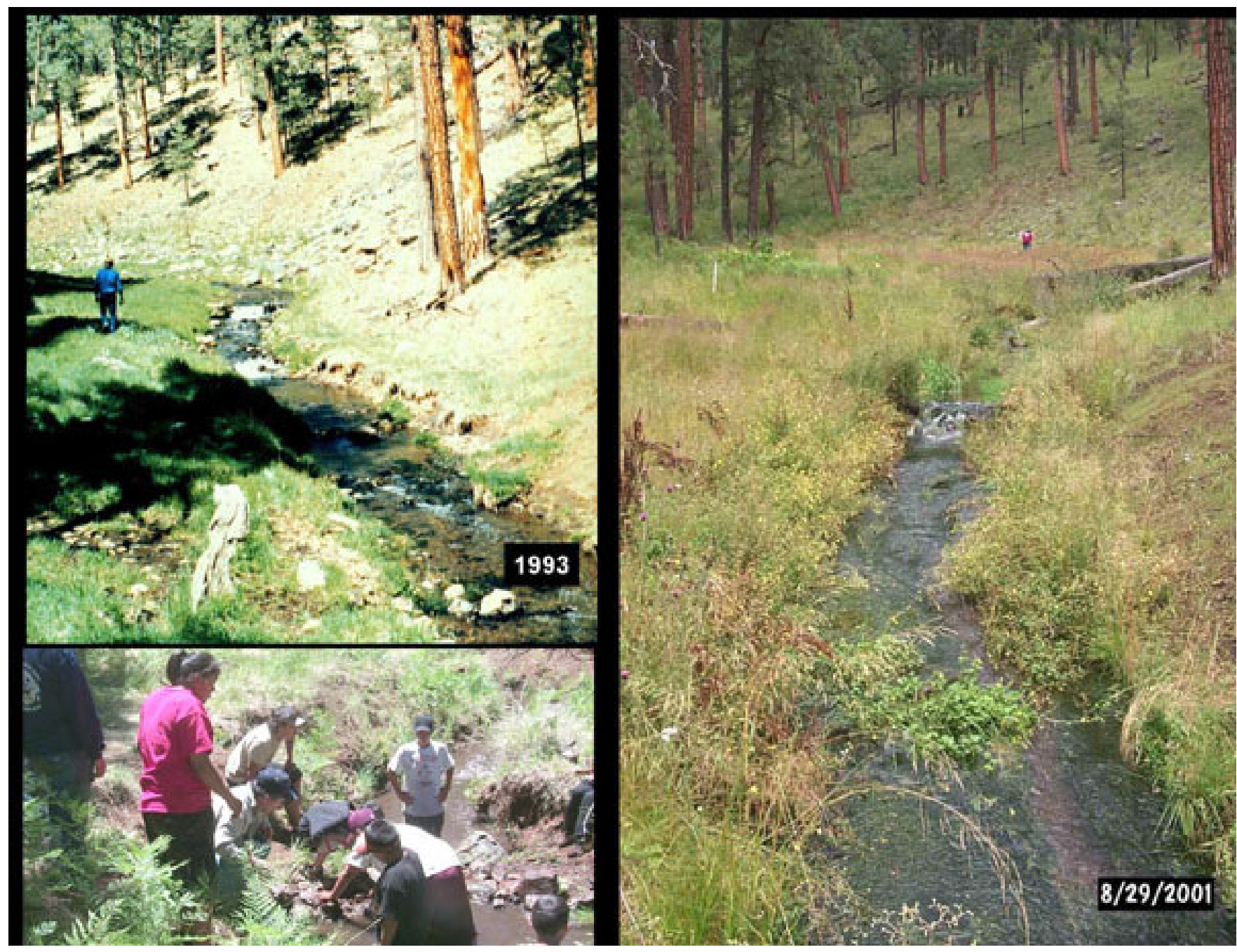

The Tribe's perspective on land management continues to inform restoration activities in ways that may run counter to restoration efforts in other parts of the United States. For example, a top priority for tribal revegetation efforts is the common reed. Denounced in the many parts of the U.S. as a troublesome and 
rapidly spreading invader (Ailstock et al. 2001), this plant has declined throughout its range in Apache country, as demonstrated by its disappearance at numerous sites named for it (Basso 1996). Therefore, despite aggressive efforts to reduce this plant in other parts of North America (Blossey and McCauley 2000), advisors have strongly advocated the transplanting of reeds as part of restoration efforts at several sites. Recent genetic research has demonstrated that nonnative genotypes have led the invasion into coastal areas, but many native genotypes may be rare and declining (Saltonstall 2002).

Reestablishment of reed is one tactic within a general strategy of promoting herbaceous vegetation where woody plants have become widespread. Although riparian restoration elsewhere in the Southwest has emphasized pole plantings, advisors characterize the historical riparian vegetation in most community areas as scattered mature trees with a grassy understory and only occasional stands of woody shrubs. Advisors viewed mature cottonwoods (Populus fremontii and $P$. angustifolia), Goodding willow (Salix gooddingii), Arizona alder (Alnus oblongifolia), and walnut (Juglans major) as indicators of good condition. However, they generally decry the invasion of shrubby species, such as the native coyote willow (Salix exigua) and the non-native Siberian elm (Ulmus pumila, referred to locally as "Chinese elm"). Despite the fact that coyote willow is valued by basketmakers and that Siberian elm provides shade, the ability of these species to rapidly invade disturbed soils has made them a nuisance in both riparian areas and traditional corn fields. Large floods reported in community areas during the late 1920 s caused channel incision and widening (Buskirk 1986), which in turn would have lowered water tables and coarsened substrates. Such conditions can set the stage for encroachment by willows and cottonwoods (Scott et al. 1996). Furthermore, findings that densely clonal, multi-stemmed woody plants can have detrimental effects on some riparian areas (Lyons et al. 2000) support the view that expansion of shrubs can signify stream deterioration. To restore streamside habitats historically dominated by herbaceous plants, thinning of riparian shrubs has become an important treatment on the Reservation.

\section{Cyclical framework}

In addition to providing insights into plant cultivation, agricultural traditions provide a general framework for caring for land and waters. The agricultural calendar reinforces the importance of cyclical patterns that are central to indigenous cosmologies (LaDuke 1994). This tradition reminds practitioners that the goal of restoration is to help a site evolve through cyclical changes, rather than establishing a preconceived state or linear trajectory (Kimmerer 2000). The Watershed Program also incorporates the cyclical framework into its program activities by planning new projects in the spring, implementing projects in the summer, assessing the results of treatments in the fall, and compiling reports and making presentations (a contemporary version of storytelling) in the winter. The use of the four colors and four directions to represent concepts such as watershed areas and geologic types also reinforces the importance of cyclical patterns in the Program's activities (Fig. 4).

Fig. 4. A logo of the Tribal Watershed Program incorporates the four directions and the four sacred colors to reinforce the cultural dimensions of its ecological management activities. Signifying the four seasons and essential ecological elements $($ white $=$ water/snow, black=earth, green=plants, and yellow=harvest or fire), these design features also convey important ecological concepts such as the four major watershed areas on the Reservation (White, Black, Carrizo, and Upper Salt) and four of the dominant geological types (felsic, volcanic, mafic volcanic, fine sedimentary, and coarse sedimentary.

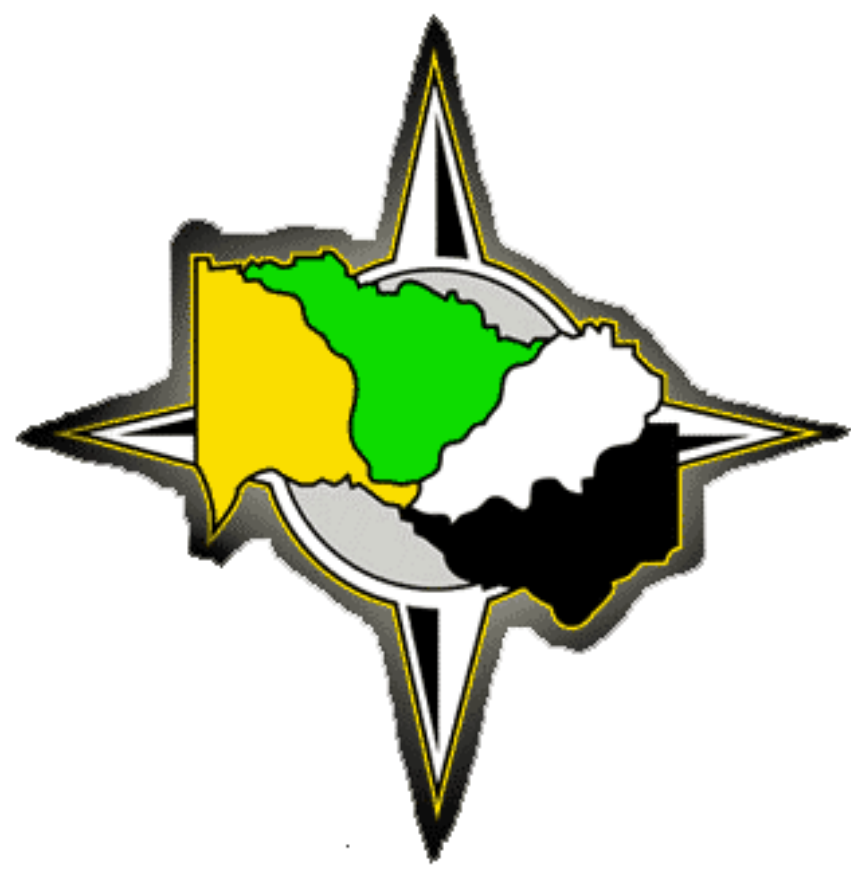


Fig. 5. A spring-fed reach on East Cedar Creek was relatively bare in 1997 (inset). Rest from season-long grazing spurred rapid growth of vibrant, herbaceous wetland plants that protect the channel from erosion.

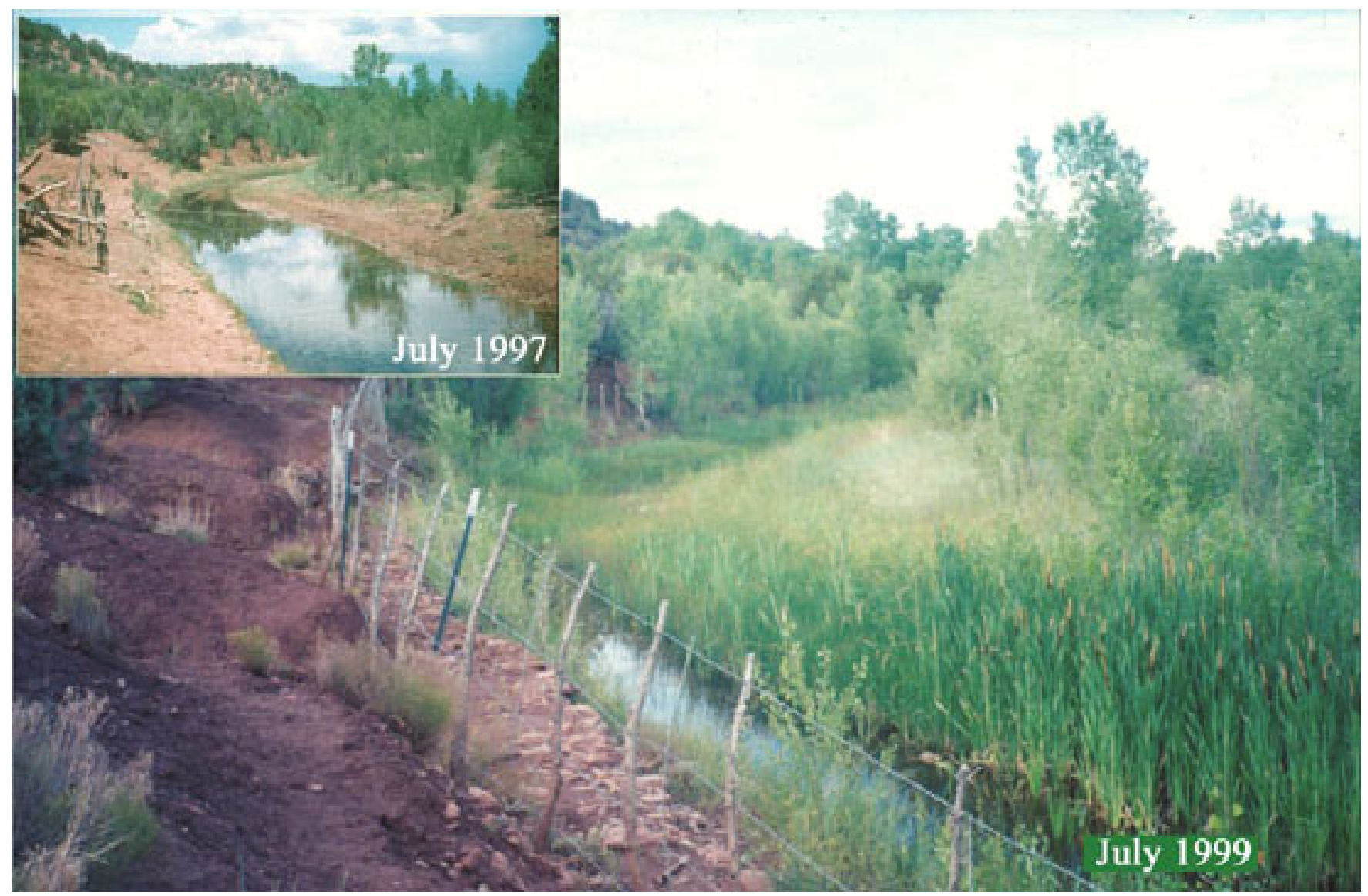

\section{PSYCHOLOGICAL AND SOCIAL DIMENSIONS OF ECOLOGICAL RESTORATION}

A worldview of reciprocal relationships between humans and ecosystems underlies caretaking traditions among indigenous peoples (LaDuke 1994, Kimmerer 2000). Elders remind the youth that people need to watch over and take care of life-sustaining resources to ensure that they will be available. Providing a practical example of such care, advisors explained that individuals who used a particular spring for irrigation or domestic use would assume responsibility for cleaning it and monitoring its flow and quality. This tradition prevents the abuse of community resources and serves as a precedent for ecological monitoring.

Although the caretaking custom benefits society as a whole, it operates through individuals. Many tribal staff members engaged in restoration activities feel a weighty responsibility of caring for a particular site. That such personal relationships develop is an outgrowth of the Tribe's practice of assigning individuals to lead restoration projects, but it also signifies much older cultural traditions. Practitioners believe that they are sent to a particular site for a reason, and that if they have a good heart and steady mind, then they will want to take care of that place. One of the authors (B. B.) has explained this belief: "The stream has life. It talks to you by its flow. If you talk to it, it will respond to you. You have to have heart to feel for the water." Improvements in a site's condition reflect on its caregiver's mental state. In this way, we see practitioners continuing the tradition of "drinking wisdom from these places" (Basso 1996). Understanding such psychological relationships may be valuable in promoting ecological restoration (Geist and Galatowitsch 1999). 
Fig. 6. Watershed Program Supervisor Benrita Mae Burnette collects pollen amidst a dense stand of common cattail (Typha latifolia) and soft-stem bulrush (Schoenoplectus validus) at the restoration site on East Cedar Creek. Because these plants are culturally significant, their abundance represents both the functional and symbolic recovery of the site.

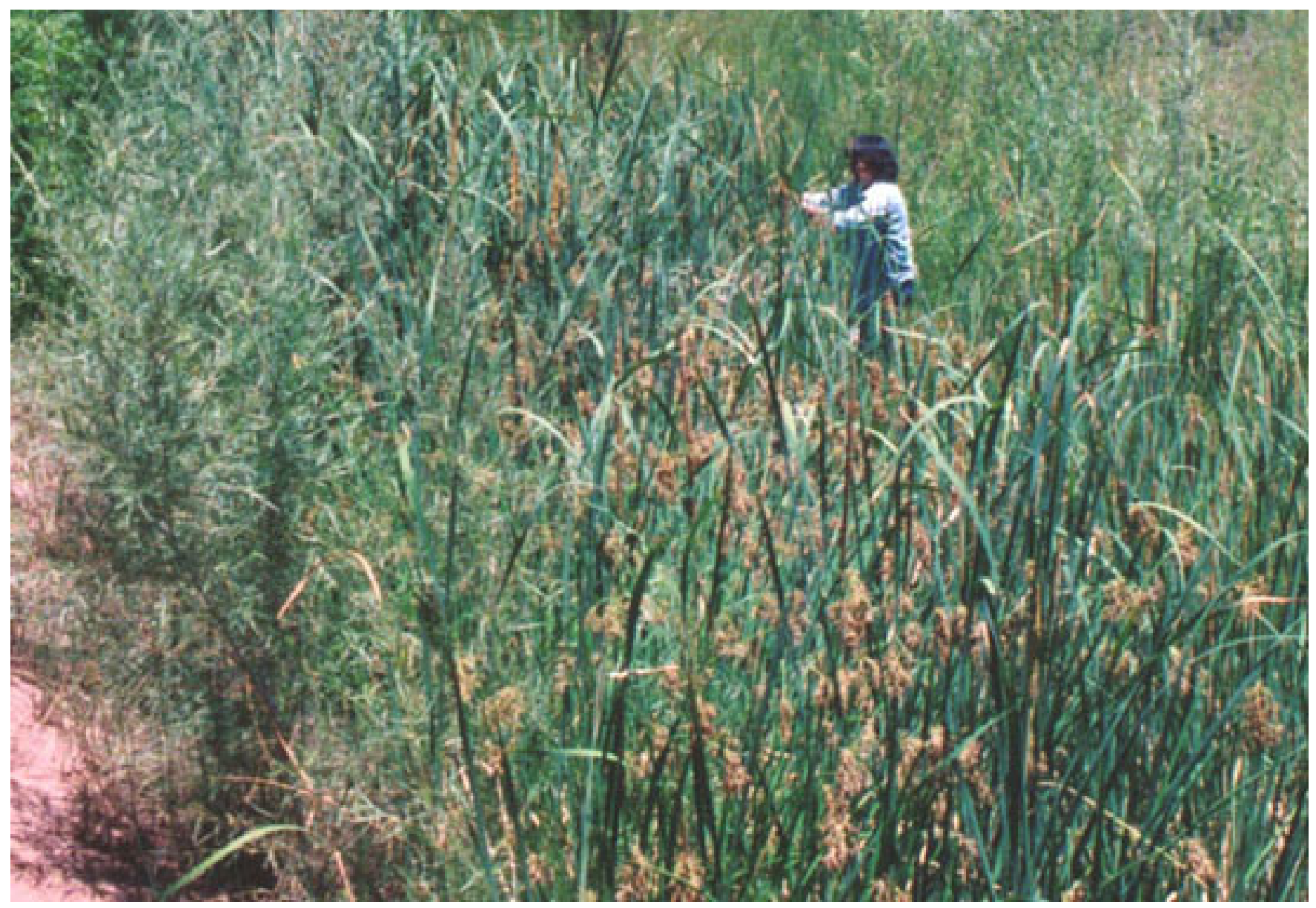

The importance of reciprocal relationships requires that restoration activities emphasize learning about the land from elders and passing on that knowledge to the youth. Advisors believe that past deterioration likely stemmed from the failure to hand down important knowledge to younger generations. Government boarding schools that removed children from their homes and banned native languages fostered such breakdowns in intergenerational knowledge transfer (Turner et al. 2000). Consequently, an important facet of the Tribe's restoration efforts has been instituting youth ecology camps and collaborations with local schools where tribal member adults teach youths how to care for their lands. Reinforced with scholarships sponsored by the Land Restoration Fund, these efforts have encouraged many young tribal members to pursue higher education in environmental fields (Long
2000). These efforts also advance restoration in more subtle ways. When practitioners serve as educators, they enhance their own learning and self-esteem (Michael 1995, Geist and Galatowitsch 1999). Passing on cultural traditions also sustains the collective action needed for successful restoration work by providing a vision for restoration, a sense of place and community, and guidance for decision-making (Geist and Galatowitsch 1999).

A guiding principle from the Tribe's experience in confronting ecological deterioration, and from indigenous peoples in general (LaDuke 1994), is that individual health, social health, and ecosystem health are interwoven. This perspective broadens ideas about how restoration ecology should develop as a discipline, because it demands consideration of the 
psychological and social implications of this work. Like many indigenous peoples, Apaches see the cause of unhealthy ecosystems not as the result of traditional philosophies, but rather as the disruption of those philosophies by external influences (Gray and Wesley 1997). The newest episode in this history is that outside forces now advocate ecological restoration as a vehicle for species conservation, but without regard for underlying economic and political disparities (Lupe 1992, Sanderson 1995). In some cases, conservation scientists may even oppose efforts to address such disparities because, "the ideal would be to have far fewer people in the rural landscape" (Young 2000). Imposing non-indigenous management paradigms runs the same risk of damaging ecosystems as have historical efforts to introduce exotic species and eliminate native species.

For the White Mountain Apache Tribe, memory of the widespread ecological deterioration that occurred in the early part of the $20^{\text {th }}$ century (Buskirk 1986, Long 1998) is being supplanted by visions of restoration sites that have made remarkable recoveries (Fig. 5). Advisors are pleased that so many of these places have demonstrated that they indeed have "life within them." Moreover, at some of these sites (Fig. 6), community members are renewing harvest of wetland plants and medicinal herbs (Long 2000). In this way, restoration efforts give back to the cultural traditions from which they grew.

Due to the guidance and institutional involvement of cultural advisors, the Tribe has cultivated its stories, place names, agricultural practices, and healing traditions to provide a conceptual and practical foundation for ecological restoration. Cultural traditions alone do not provide sufficient knowledge to ensure sustainability, because human cultures have evolved over relatively short periods, and because people inevitably forget some of the knowledge of their ancestors, such as how to cope with different climates (Jackson 1997). Yet cultural traditions also guide how the culture itself can adapt to changing environmental demands. Apache culture has a long history of selectively adopting outside elements, but within a distinctive context that demands individual responsibility and cultural compatibility (Everett 1971). Consequently, tribal member professionals currently monitor the outcomes of restoration treatments using quantitative scientific methods and engage in restoration research with outside scientists. Although scientific inquiry continues to advance the Tribe's knowledge of how to restore its lands and waters, this profoundly cultural endeavor remains firmly rooted in ancient concepts. Just as they did hundreds of years ago, places remind us that renewal in all forms, individual, social, and ecological, is part of the cycle of life: "The names of all these places are good. They make you remember how to live right, so you want to replace yourself again" (Nick Thompson quoted in Basso 1996: 59). Like any other ecological resource, cultural knowledge can dry up if neglected; but by bringing it to bear on the evolving challenges of ecological deterioration, it can breathe again.

Responses to this article can be read online at: http://www.consecol.org/vol8/iss1/art3/responses/index.html

\section{Acknowledgments:}

We wish to thank the White Mountain Apache Tribe for telling the story of their restoration efforts. Special appreciation goes to the primary advisors who visited restoration sites and shared their knowledge of riparian health: Eva Watt, Cornelia Hoffman, Raymond Kane, and Isaac Kasey. We give additional thanks to Beverly Malone, Genevieve Endfield, Marilyn Lovato, Ramon Riley, Levi DeHose, Jerome Kasey, Delbin Endfield, Derald Declay, the Tribal Cultural Advisory Board, Keith Basso, Gayle Potter Basso, Bob Brauchli, Sylvia Cates, and Alvin Medina for providing advice and insights over the past several years. However, responsibility for any misinterpretations or other errors lies with the authors. A Ford Foundation Community Forestry Research Fellowship and an EPA STAR Research Fellowship (Grant \#U915717) provided primary funding for this research. The National Science Foundation's Sustainability for Semi-Arid Hydrology and Riparian Areas (SAHRA) (Grant \#Y542104) also partially supported the research.

\section{LITERATURE CITED}

Ailstock, M. S., C. M. Norman, and P. J. Bushmann. 2001. Common reed Phragmites australis: control and effect upon biodiversity in freshwater nontidal wetlands. Restoration Ecology 9:49-59.

Allen, T. F. H., and T. W. Hoekstra. 1992. Toward a unified ecology. Columbia University Press, New York, New York, USA.

Basso, K. H. 1970. The Cibecue Apache. Waveland Press, Prospect Heights, Illinois, USA.

Basso, K. H. 1996. Wisdom Sits in Places. University of New Mexico Press, Albuquerque, New Mexico, USA. 
Berkes, F., J. Colding, and C. Folke. 2000. Rediscovery of traditional ecological knowledge as adaptive management. Ecological Applications 10:1251-1262.

Blossey, B., and J. McCauley. 2000. A plan for developing biological control of Phragmites australis in North America. Wetland Journal 12:23-28.

Bray, D., editor. 1999. Western Apache English Dictionary. Bilingual Review Press, Tempe, Arizona, USA.

Buskirk, W. 1986. The Western Apache: Living with the Land before 1950. University of Oklahoma Press, Norman, Oklahoma, USA.

Callicott, J. B. 1989. Traditional American Indian and western European attitudes toward nature: an overview. Pages 177-201 inJ. B. Callicott and D. E. Shaner, editors. Defense of land ethics: essays in environmental philosophy. University of New York Press, New York, New York, USA.

Crouse, C. W. 1902. Report of Fort Apache. Pages 147151 in The Annual Report of the Commissioner of Indian Affairs to the Secretary of the Interior for the Year 1902. U.S. Government Printing Office, Washington, D.C., USA.

Des Jardins, J. R. 1997. Environmental ethics: an introduction to environmental philosophy. Wadsworth Publishing Company, Belmont, California, USA.

Everett, M. W. 1971. White Mountain Apache Health and Illness: an Ethnographic Study of Medical Decisionmaking. Dissertation. University of Arizona, Tucson, Arizona, USA.

Ford, J., and D. Martinez. 2000. Traditional ecological knowledge, ecosystem science, and environmental management. Ecological Applications 10(5):1249-1250.

Geist, C., and S. M. Galatowitsch. 1999. Reciprocal model for meeting ecological and human needs in restoration projects. Conservation Biology 13:970-979.

Goodwin, G. 1938. White Mountain Apache religion. American Anthropologist 40:24-37.

Goodwin, G. 1994. Myths and Tales of the White Mountain Apache. The University of Arizona Press, Tucson, Arizona, USA.

Gray, R. W., and V. Wesley. 1997. Reconciling traditional Apache and western natural resource management philosophies on the San Carlos Apache Reservation. Pages 150-155 in Society of American Foresters. Diverse forests, abundant opportunities, and evolving realities: Proceedings of the 1996 Society of American Foresters Convention, Albuquerque, New Mexico, November 9-13, 1996. Bethesda, Maryland, USA.

Grenville Goodwin Placenames Project. 1997. Unpublished report to the Western Apache Coalition. Courtesy of White Mountain Apache Tribal Heritage
Program, Whiteriver, Arizona, USA.

Grimm, V., and C. Wissel. 1997. Babel, or the ecological stability discussions: an inventory and analysis of terminology and a guide for avoiding confusion. Oecologia 109:323-334.

Gunderson, L. H., C. S. Holling, and S. S. Light. 1995. Barriers broken and bridges built: a synthesis. Pages 375390 in L. H. Gunderson, C. S. Holling, and S. S. Light, editors. Barriers and bridges to the renewal of ecosystems and institutions. Columbia University Press, New York, New York, USA.

Hargrove, E. C. 1992. Environmental therapeutic nihilism. Pages 124-131 in R. Costanza, B. Norton, and B. Haskel, editors. Ecosystem health: new goals for environmental management. Island Press, Washington, D.C., USA.

Hendrickson, D. A., and W. L. Minckley. 1984. Ciénegas-vanishing climax communities of the American Southwest. Desert Plants 6:130-175.

Hobbs, R. J., and J. B. Norton. 1996. Towards a conceptual framework for restoration ecology. Restoration Ecology 4: 93-100.

Jackson, W. 1997. Call for a revolution in agriculture. Pages 259-264 in Hildegaard Hannum, editor. People, land, and community: collected E.F. Schumacher Society lectures. Yale University Press, New Haven, Connecticut, USA.

Kelly, J. R., and M. A. Harwell. 1990. Indicators of ecosystem recovery. Environmental Management 14:527545.

Kimmerer, R. W. 2000. Native knowledge for native ecosystems. Journal of Forestry 98:4-9.

LaDuke, W. 1994. Traditional ecological knowledge and environmental futures. Colorado Journal of International Environmental Law and Policy 5:127-148.

Lal, P., H. Lim-Applegate, and M. Scoccimarro. 2001. The adaptive decision-making process as a tool for integrated natural resource management: focus, attitudes, and approach. Conservation Ecology 5(2): 11. [Online] URL: http://www.consecol.org/vol5/iss2/art11.

Leopold, A. S. 1939. A biotic view of land. Journal of Forestry 37:727-730.

Leopold, A. S. 1999. For the health of the land: previously unpublished essays and other writings. J. B. Callicott and E. T. Freyfogle, editors. Island Press, Washington, D.C., USA.

Lewis, H. T. 1989. Ecological knowledge of fire: Aborigines vs. park rangers in Northern Australia. American Anthropologist 91(4):940-961.

Long, J. W. 1998. Restoring the land and mind. Journal of Land, Resources and Environmental Law 18:51-61. 
Long, J. W. 2000. Cibecue watershed projects: then, now, and in the future. Pages 227-233 in P. F. Folliott, M. B. Baker Jr., C. B. Edminster, B. Carleton, M. C. Dillion, and K. C. Mora, technical editors. Proceedings of land stewardship in the 21st Century: the contributions of watershed management. March 13-16, 2000, Tucson, Arizona. RMRS-P-13. U.S. Department of Agriculture, Forest Service, Rocky Mountain Research Station, Fort Collins, Colorado, USA.

Long, J. W., and B. M. Burnette. 2000. Restoration of Soldier Spring. Pages 361-362 in P. F. Folliott, M. B. Baker Jr., C. B. Edminster, B. Carleton, M. C. Dillion, and K. C. Mora, technical editors. Proceedings of land stewardship in the 21st Century: the contributions of watershed management. March 13-16, 2000, Tucson, Arizona. RMRSP-13. U.S. Department of Agriculture, Forest Service, Rocky Mountain Research Station, Fort Collins, Colorado, USA.

Lupe, R. 1992. The Challenges of Leadership and Selfgovernment: a Perspective of the White Mountain Apaches. (Speech.) Harvard Project on American Indian Economic Development Project Report Series 92-5. Harvard University, Cambridge, Massachussetts, USA.

Lyons, J., S. W. Trimble, and L. K. Paine. 2000. Grass versus trees: managing riparian areas to benefit streams of central North America. Journal of the American Water Resources Association 36:919-930.

Martinez, D. 1995. Karuk tribal module of mainstem salmon watershed analysis: Karuk ancestral lands and people as reference ecosystem for eco-cultural restoration in collaborative ecosystem management. Unpublished report. On file with: U.S. Department of Agriculture, Forest Service, Klamath National Forest, 1312 Fairlane Road, Yreka, CA 96097. Contract \#43-91W8-5-7017.

Michael, D. N. 1995. Barriers and bridges to learning in a turbulent human ecology. Pages 461-488 in L. H. Gunderson, C. S. Holling, and S. S. Light, editors. Barriers and bridges to the renewal of ecosystems and institutions. Columbia University Press, New York, New York, USA.

Nabhan, G. P. 1997. Cultures of Habitat. Counterpoint, Washington, D.C., USA.

Naveh, Z. 1998. Ecological and cultural landscape restoration and the cultural evolution toward a postindustrial symbiosis between human society and nature. Restoration Ecology 6:135-143.

Neary, D. G., and G. J. Gottfried. 2002. Fires and floods: post-fire watershed responses. Pages 1-9 in D. X. Viegas, editor. Forest fire research and wildland fire safety. Millpress, Rotterdam, The Netherlands.

Neary, D. G., G. J. Gottfried, L. F. DeBano, and A. Tecle. 2003. Impacts of fire on watershed resources. Journal of the Arizona-Nevada Academy of Science
35(1):23-41.

Pyne, S. J. 1997. Fire in America: a Cultural History of Wildland and Rural Fire. University of Washington Press, Seattle, Washington, USA.

Saltonstall, K. 2002. Cryptic invasion by a non-native genotype of the common reed, Phragmites australis, into North America. Proceedings of the National Academy of Sciences 99(4):2445-2449.

Sanderson, S. E. 1995. Ten theses on the promise and problems of creative ecosystem management in developing countries. Pages 375-390 in L. H. Gunderson, C. S. Holling, and S. S. Light, editors. Barriers and bridges to the renewal of ecosystems and institutions. Columbia University Press, New York, New York, USA.

Society for Ecological Restoration Science and Policy Working Group. 2002. The SER Primer on Ecological Restoration. (Online) URL: http://www.ser.org/.

Scott, M. L., J. M. Friedman, and G. T. Auble. 1996. Fluvial process and the establishment of bottomland trees. Geomorphology 14:327-339.

Turner, N. J., M. B. Ignace, and R. Ignace. 2000. Traditional ecological knowledge and wisdom of aboriginal peoples in British Columbia. Ecological Applications 10:1275-1287.

van Diggelen, R., A. P. Grootjans, and J. A. Harris. 2001. Ecological restoration: state of the art or state of the science? Restoration Ecology 9:115-118.

Welch, J. A. 1998. Working together: White Mountain Apache Heritage Program operations and challenges. Society for American Archaeology Bulletin 16.

Young, T. 2000. Restoration ecology and conservation biology. Biological Conservation 92:73-83. 